\title{
Influence of body composition, muscle strength, diet and physical activity on total body and forearm bone mass in Chinese adolescent girls
}

\author{
Leng Huat Foo ${ }^{1,3 *}$, Qian Zhang ${ }^{1}$, Kun Zhu ${ }^{1}$, Guansheng $\mathrm{Ma}^{2}$, Heather Greenfield ${ }^{1}$ and David R. Fraser ${ }^{1}$ \\ ${ }^{1}$ Faculty of Veterinary Science, University of Sydney, Sydney, NSW 2006, Australia \\ ${ }^{2}$ National Institute for Nutrition and Food Safety, Chinese Center for Disease Control and Prevention, Beijing 100050, China \\ ${ }^{3}$ School of Health Sciences, Universiti Sains Malaysia, Kubang Kerian, Kelantan 16150, Malaysia
}

(Received 7 February 2007 - Revised 23 April 2007 - Accepted 21 May 2007)

The aim of the present study was to determine association between body composition, muscle strength, diet and physical exercise with bone mineral content (BMC) and bone area (BA) in 283 Chinese adolescent girls aged 15 years in Beijing, China. Body composition, pubertal stage, physical activity and dietary intakes were assessed using standard validated protocols. Total body and forearm bone, lean body mass (LBM) and fat body mass (FBM) were determined by dual X-ray absorptiometry. Multivariate linear regression analyses were carried out to examine the predictors of BMC and BA, after controlling for potential confounders. The subjects had a mean age of 15.0 (SD 0.9 ) years and $99.6 \%$ of them had reached menarche. Multivariate analyses showed that LBM, FBM, handgrip muscle strength and milk intake were significant independent determinants of BMC and BA of the total body and/or forearm sites. LBM was found to be a stronger independent determinant than FBM of BMC and BA, whereas handgrip muscle strength was only found as significant determinant of BMC and BA at the forearm sites than in total body BMC and BA. Further, total physical activity level had a significant positive association with handgrip and LBM. This suggested that greater muscle strength and higher LBM may reflect higher levels of physical activity. Therefore, continuous healthy lifestyle practices such as adequate intake of milk and continuous participation in physical activity should be encouraged throughout adolescence to optimise bone growth during this period.

Body composition: Handgrip muscle strength: Milk: Physical activity: Adolescent girls

Medical efforts towards fracture prevention have been aimed at retarding the rate of age-related bone loss in the elderly. However, there is evidence suggesting that the risk of osteoporotic fractures in later life may be associated with the quantity of bone mass acquired in childhood and adolescence. Thus, osteoporosis may be caused by inadequate bone mass accretion rather than by just excessive bone loss in old age ${ }^{1}$. As life expectancy increases in Asian populations, the prevalence of osteoporosis is expected to rise; making it a significant health challenge in Asia in the next few decades ${ }^{2}$.

Peak bone mass is defined as the maximum amount of bone when skeletal maturation is complete, with most skeletal accretion occurring between the ages of 10 and 20 years ${ }^{1}$. Although peak bone mass is mainly determined by genetics, other factors, such as nutrition and physical exercise, can modify the level of bone mineral deposition during adolescence. There has been much research in Caucasian children and adolescents, which relates body composition and environmental factors to bone mass accretion, but there have been relatively few studies on Chinese post-menarcheal adolescent girls ${ }^{3}$. An understanding of the factors that influence bone mass accretion could help develop strategies to maximise bone mineral deposition during childhood and adolescence, which could help prevent osteoporosis-related fractures later in life. Intervention is likely to be more effective with children and adolescents, because later in life when fractures are likely, the loss of bone mass is very difficult to reverse completely. Therefore, the aim of the present study was to examine whether there is association between body composition, handgrip muscle strength, dietary intake and physical exercise with bone mineral content (BMC) and bone area (BA) and then to identify any interdependence and predictive strength of these variables on total body and forearm skeletal bone mass in Chinese adolescent girls at 15 years of age in Beijing, China.

\section{Materials and methods}

Subjects

A cohort of 504 adolescent girls in Beijing was investigated to determine whether there was any relationship between genetic, pubertal and nutritional factors and physical activity with bone mass accretion. This cohort had been recruited previously as part of a 5-year dietary intervention study. Details of the recruitment procedures have been described elsewhere ${ }^{4,5}$. It was found that 3 years after completing a 2-year milk supplementation study, all the benefits derived from the milk supplement on bone mass and body size had disappeared ${ }^{5}$. 
A random subset of subjects ( $n$ 283) had their total body bone mineral measurements taken. In addition, there were no significant differences found in body composition parameters, handgrip muscle strength, stage of pubertal development, dietary intakes and physical activity level between subjects who had completed their total body bone measurements and those who had not. Therefore, all the 283 girls were included in this cross-sectional analysis to determine whether any independent factors were associated with bone mass quantity. None of the subjects had clinical signs of bone disease that could potentially prevent them from being physically active, nor were they taking any medications known to influence bone metabolism. The study was approved jointly by the Human Ethics Review Committee of The University of Sydney and that of the National Institute for Nutrition and Food Safety, China Centers of Disease Control and Prevention. Written informed consent was also obtained from both subjects and their parents or guardians prior to examination.

Body composition, handgrip muscle strength and Tanner pubertal stage measurements

Anthropometric measurements such as body weight and height were performed using standardised procedures. Subjects were weighed (wearing light clothing and without shoes) to the nearest $0.1 \mathrm{~kg}$ with an electronic digital scale (Thinner, Fairfield, WI, USA). Height of subjects with bare feet was measured to the nearest $0.1 \mathrm{~cm}$, using a body height measuring stadiometer (TG-III Type; No. 6 Machinery Plant, Beijing, China) at the hospital where the dual-energy X-ray absorptiometry scans were carried out. All anthropometric measurements were taken twice and an average value was calculated. BMI was calculated as body weight $(\mathrm{kg})$ divided by height $\left(\mathrm{m}^{2}\right)$. Handgrip strength was measured on both non-dominant and dominant hands using a hand-held dynamometer with adjustable widths (model 78010; Lafayette Instrument Company, Lafayette, IN, USA). Subjects were instructed to squeeze the dynamometer as hard as possible for $3 \mathrm{~s}$, without pressing the instrument against their body or bending at the elbow. Two measurements were taken at 1 - to 2-min intervals and the greater of the two handgrip values was used in the final analysis. The $\mathrm{CV}$ for repeated measurements ( $n$ 10) was $1.7 \%$. Breast development and pubic hair development were assessed according to Tanner's definitions of the five stages of puberty ${ }^{6}$. When there were discrepancies between breast and pubic hair assessment, breast development was used as the determining criterion for stage of pubertal development. Age at menarche was also ascertained and recorded.

\section{Bone age and bone mass measurements}

Bone age was determined using the Greulich and Pyle Atlas method $^{7}$. Radiological examination of the left hand and wrist of each subject was carried out using the standard protocol of the Department of Radiology (304 Military Hospital of Beijing, China). Skeletal age to the nearest 3 months was determined from the stage of growth of the metacarpals, phalanges and carpal bones in reference to a set of CHN method-China Population Skeletal Development Standard photographs). Total body and distal and proximal forearm bone masses were determined using dual-energy X-ray absorptiometry (XR-36; Norland Medical Systems Inc., Fort Atkinson, WI, USA). All bone measurements were performed by the same two trained technicians, who were unaware of into which earlier treatment groups the subjects had been placed. To minimise technical variation, all bone data were analysed by the same person, using the Norland enhanced software version 3.9.4. Quality control scans were performed each day. Prior to each scan, the densitometer was calibrated according to the manufacturer's recommendations. During the course of the study (2-6 months), the precision of repeated measurements $(\mathrm{CV})$ using a manufacturer-supplied phantom was $<1 \%$, indicating satisfactory long-term stability of the instrument with no sign of drift. Additionally, a shortterm precision measurement was made each day using the same phantom, which gave CV $0 \cdot 31 \%$. To minimise radiation exposure, no repeat scans were done on any child. In the present study, BMC and BA of the total body and of the distal and proximal forearm were used as primary dependent variables. It is now apparent that that areal bone mineral density (BMD) should not be used as a measure of bone mineral status during growth ${ }^{8}$. Lean body mass (LBM) and fat body mass (FBM) were also obtained from the bone densitometer data, from which percentage body fat was also calculated.

\section{Assessment of physical activity and dietary intake}

Habitual physical activity over the previous 12 months was assessed using a structured and detailed Modifiable Activity Questionnaire for Adolescents9, which was modified to include physical activities commonly practised by Chinese school children. This physical activity has been proven to give reliable and valid estimates of physical activity in Beijing school children ${ }^{10}$. Both qualitative and quantitative information was collected over a 12-month time interval to cover seasonal and variation in the type, frequency, intensity and duration of activities and participation in organised sport, either at school or during leisure time. Furthermore, the questionnaire also solicited information on the pattern of physical inactivity during weekdays and at the weekend, such as the time spent in reading, watching television and playing with a computer. Four levels of physical impact were used, namely, none, low, moderate or high impact based on the classification used in the EPIC Norfolk study ${ }^{11}$ and expressed as total hours per week.

Dietary intakes were assessed from two 3-day food records, which included two week days and one weekend day. Chinese measures of bowls, plates and spoons of standard size were used to quantify food items with the assistance of a set of food measure models and a trained interviewer. Because data on the content of vitamin D in Chinese food were not available, vitamin D food values were obtained from the UK food composition tables ${ }^{12}$, with an adjusted decrease in the values for vitamin $\mathrm{D}$ in eggs and in fortified fresh milk based on local analyses of these foods in China ${ }^{4}$.

\section{Statistical analysis}

Descriptive statistics are reported as mean values and standard deviations and any differences as means with their standard errors for all variables, unless otherwise indicated. Analysis 
using bivariate correlation coefficients examined the direction and magnitude of the relationship between the bone mass measurements and other explanatory continuous variables. Analysis of covariance was used, with post-hoc Bonferroni's correction for multiple comparisons to assess the relationships between physical activity tertiles and different body composition measures and handgrip muscle strength, after adjusting for potential confounding factors. FBM and LBM were entered instead of body weight, as the sum of these parameters represents total body weight. A multiple regression model with stepwise elimination was used to assess the influence of differences in body composition, pubertal stage development, muscle strength, dietary intakes and physical activity on BMC and BA. Since body size indicators, such as body weight, height and $\mathrm{BA}$ were strong predictors of $\mathrm{BMC}$, these factors were given higher priority in the regression models to minimise the size-artefacts on bone mass in growing adolescents ${ }^{8}$. Where appropriate, interaction between physical activity and body composition, handgrip muscle strength and dietary intake factors was also tested. A similar approach was followed to determine whether there was any association between body composition, physical activity and nutrition on bone size, where BA was then treated as a dependent variable. Possible inter-associations between all independent variables were also sought using collinearity diagnostics tests. Results from all separate models were expressed as regression coefficients $(\beta)$ and standard errors. The relative importance of all explanatory variables included in all the models and the adjusted $R^{2}$ for each regression model as well as the partial coefficient of adjusted $R^{2}$ for each significant explanatory variable was also determined. Statistical analysis was carried out using SPSS version 12.0 for Windows (SPSS Inc., Chicago, IL, USA) and statistical significance for all the tests was defined by a $P$ value $<0.05$.

\section{Results}

\section{General characteristics}

General characteristics, body composition, handgrip muscle strength, stage of pubertal development, physical activity levels and nutrient intake of the subjects are presented in Table 1. Mean age of the subjects was 15.0 (SD 0.5) years and average bone age was 16.0 (SD 0.9) years. The mean BMI of all subjects was $21 \cdot 1$ (SD 3.5$) \mathrm{kg} / \mathrm{m}^{2}$ with approximately $80.6 \%$ being in the normal range. Only a small number were classified as at risk of obesity $(3.9 \%)$ or were overweight $(15.5 \%)$ based on the recent international cut-off points recommended by the International Obesity Task Force $^{13}$.

Mean handgrip muscle strength of the non-dominant and dominant hands was 23.4 (SD 4.1) $\mathrm{kg}$ and 25.3 (SD 4.3) kg, respectively, with that of the dominant hand being significantly higher than the non-dominant hand (Paired $t$ test 18.513; $P<0.001)$. Most of the girls had reached pubertal Tanner breast and pubic hair stages IV and V $(96.5 \%$ and $84.7 \%$, respectively), indicating that most were post-pubertal at the time of assessment.

Analysis of physical activity by intensity of impact, as defined by Jakes et $a{ }^{11}{ }^{11}$, showed that the time spent in none-to-low impact and in moderate-to-high impact physical
Table 1. General characteristics, body composition, pubertal status, physical activity and dietary factors measures of Chinese adolescents girls*

(Mean values and standard deviations for 283 subjects)

\begin{tabular}{|c|c|c|}
\hline & Mean & SD \\
\hline Age (years) & $15 \cdot 0$ & 0.5 \\
\hline Bone age (years) & $16 \cdot 0$ & $0 \cdot 8$ \\
\hline Body weight (kg) & $55 \cdot 4$ & $9 \cdot 7$ \\
\hline Height $(\mathrm{m})$ & 1.61 & 0.05 \\
\hline BMI $\left(\mathrm{kg} / \mathrm{m}^{2}\right)$ & $21 \cdot 2$ & $3 \cdot 4$ \\
\hline \multicolumn{3}{|l|}{ Handgrip muscle strength $(\mathrm{kg})$} \\
\hline Non-dominant hand & $23 \cdot 4$ & $4 \cdot 1$ \\
\hline Dominant hand & $25 \cdot 4$ & 4.4 \\
\hline Pubertal breast development & $4 \cdot 4$ & 0.6 \\
\hline Pubertal pubic hair & $4 \cdot 2$ & 0.8 \\
\hline Age at menarche (years) & $12 \cdot 3$ & $0 \cdot 8$ \\
\hline \multicolumn{3}{|l|}{ Menarche status (Yes) } \\
\hline$\%$ & \multicolumn{2}{|c|}{$99 \cdot 6$} \\
\hline$n$ & \multicolumn{2}{|c|}{282} \\
\hline Total physical activity (PA) (h/week) & $10 \cdot 2$ & $7 \cdot 6$ \\
\hline Non to low-impact PA (h/week) & $2 \cdot 0$ & $2 \cdot 8$ \\
\hline Moderate to high-impact PA (h/week) & $8 \cdot 2$ & $6 \cdot 6$ \\
\hline \multicolumn{3}{|l|}{ Sports participation status (Yes) } \\
\hline$\%$ & \multicolumn{2}{|c|}{$15 \cdot 5$} \\
\hline$n$ & \multicolumn{2}{|c|}{44} \\
\hline Ca intake (mg/d) & $475 \cdot 1$ & $228 \cdot 6$ \\
\hline Vitamin D intake $(\mu \mathrm{g} / \mathrm{d})$ & 0.48 & 0.55 \\
\hline$P$ intake $(\mathrm{mg} / \mathrm{d})$ & $812 \cdot 8$ & $242 \cdot 8$ \\
\hline Milk intake (g/d) & $142 \cdot 2$ & $116 \cdot 1$ \\
\hline
\end{tabular}

${ }^{*}$ For details of subjects and procedures, see Materials and methods.

activity were respectively $2.0(\mathrm{SD} 2.8)$ and $8.2(\mathrm{SD} 6.6) \mathrm{h} /$ week. Only $15.5 \%$ of the subjects $(n 44)$ reported participation in organised sports training either inside or outside school. The average intakes of dietary $\mathrm{Ca}$, vitamin $\mathrm{D}$ and milk were $475 \cdot 1$ (SD 228.6) $\mathrm{mg} / \mathrm{d}, 0.48$ (SD 0.55) $\mu \mathrm{g} / \mathrm{d}$ and 142.2 (SD 116.1) g/d, respectively.

\section{Multivariate analysis}

Table 2 shows the results of multivariate regression analyses for total body and distal and proximal forearm BMC. Similar analyses for independent predictor variables of BA at all the skeletal sites are also shown (Table 3 ). When body composition, handgrip muscle strength, stage of puberty, dietary intake and physical activity were included in the multivariate regression models, the significant independent predictors of BMC of the total body were LBM $(P<0.0001)$, BA $(P<0.0001)$, FBM $(P<0.0001)$ and milk intake $(P<0.0001)$. All these factors together accounted for $77 \%$ of the variance for total body BMC (Table 2). In the distal forearm BMC model, BA $(P<0.0001)$, LBM $(P<0.0001)$, milk intake $(P<0.05)$ and height $(P<0.05)$ emerged as the main independent variables for BMC of the distal forearm, accounting for about $43 \%$ of the variance for the distal forearm BMC. Only BA $(P<0.0001)$, LBM $(P<0 \cdot 0001)$, handgrip muscle strength $(P<0.0001)$ and milk intake $(P<0.0001)$ emerged as positive independent predictors for proximal forearm BMC. Total non-impact physical activity was a significant inverse predictor of BMC $(P<0 \cdot 01)$, accounting for $68 \%$ of the total variance for proximal forearm BMC. BA accounted for a variance range of $8.6-54.7 \%$ for BMC of all skeletal 
Table 2. Multivariate regression model predicting total body and forearm bone mineral content (BMC) in Chinese adolescent girls*

(Mean values with their standard errors)

\begin{tabular}{|c|c|c|c|c|}
\hline & $\beta$ & SE & Partial $R^{2}$ & $P$ value \\
\hline \multicolumn{5}{|l|}{ TBBMC } \\
\hline LBM (kg) & $22 \cdot 830$ & $2 \cdot 745$ & 0.645 & $<0.0001$ \\
\hline $\mathrm{BA}(\mathrm{g})$ & 0.700 & 0.074 & 0.086 & $<0.0001$ \\
\hline FBM (kg) & $9 \cdot 853$ & 1.780 & 0.029 & $<0.0001$ \\
\hline Milk intake (g/d) & 0.265 & 0.074 & 0.013 & $<0.0001$ \\
\hline Constant & -515.63 & $151 \cdot 143$ & & \\
\hline Adjusted $R^{2}$ & \multicolumn{2}{|c|}{0.770} & & \\
\hline \multicolumn{5}{|l|}{ DFBMC } \\
\hline $\mathrm{BA}(\mathrm{g})$ & 0.305 & 0.036 & 0.313 & $<0.0001$ \\
\hline LBM (kg) & 0.014 & 0.002 & 0.098 & $<0.0001$ \\
\hline Milk intake (g/d) & 0.000 & 0.000 & 0.015 & 0.04 \\
\hline Height $(\mathrm{m})$ & -0.393 & 0.191 & 0.011 & 0.04 \\
\hline Constant & 0.176 & 0.279 & & \\
\hline Adjusted $R^{2}$ & \multicolumn{2}{|c|}{0.427} & & \\
\hline \multicolumn{5}{|l|}{ PFBMC } \\
\hline $\mathrm{BA}(\mathrm{g})$ & 0.596 & 0.053 & 0.547 & $<0.0001$ \\
\hline LBM (kg) & 0.010 & 0.002 & 0.088 & $<0.0001$ \\
\hline $\begin{array}{l}\text { Handgrip } \\
\text { strength }(\mathrm{kg})\end{array}$ & $0 \cdot 154$ & 0.042 & 0.019 & $<0.0001$ \\
\hline Milk intake (g/d) & 0.000 & 0.000 & 0.019 & $<0.0001$ \\
\hline $\begin{array}{l}\text { Non-impact PA } \\
(\mathrm{h} / \text { week })\end{array}$ & $-0 \cdot 0 \cdot 13$ & 0.005 & 0.010 & 0.009 \\
\hline Constant & -0.643 & 0.127 & & $<0.0001$ \\
\hline Adjusted $R^{2}$ & \multicolumn{2}{|c|}{0.673} & & \\
\hline
\end{tabular}

*For details of subjects and procedures, see Materials and methods.

TB, total body; LBM, lean body mass; BA, bone area; FBM, fat body mass; DF, distal forearm; PF, proximal forearm; PA, physical activity.

sites. The relationship between LBM and BMC was much stronger than the relationship between FBM and BMC at all skeletal sites. The overall $R^{2}$ of BMC that could be explained by LBM was $8.8-64.5 \%$, whereas the contribution of FBM to

Table 3. Multivariate regression model predicting total body and forearm bone area (BA) in Chinese adolescent girls*

(Mean values with their standard errors)

\begin{tabular}{|c|c|c|c|c|}
\hline & $\beta$ & SE & Partial $R^{2}$ & $P$ value \\
\hline \multicolumn{5}{|l|}{ TBBA } \\
\hline Height (m) & $1800 \cdot 617$ & $121 \cdot 011$ & 0.628 & $<0.0001$ \\
\hline LBM $(\mathrm{kg})$ & $7 \cdot 388$ & 1.719 & 0.071 & $<0.0001$ \\
\hline FBM (kg) & 2.546 & $1 \cdot 159$ & 0.010 & 0.029 \\
\hline Constant & -664.607 & $174 \cdot 561$ & & $<0.0001$ \\
\hline Adjusted $R^{2}$ & \multicolumn{2}{|c|}{0.698} & & \\
\hline \multicolumn{5}{|l|}{ DFBA } \\
\hline $\begin{array}{l}\text { Handgrip } \\
\text { strength }(\mathrm{kg})\end{array}$ & 0.374 & 0.092 & $0 \cdot 110$ & $<0.0001$ \\
\hline Height (m) & $1 \cdot 156$ & 0.303 & 0.048 & $<0.0001$ \\
\hline Pubertal stage & 0.069 & 0.028 & 0.022 & 0.014 \\
\hline Constant & 0.287 & 0.508 & & 0.573 \\
\hline Adjusted $R^{2}$ & \multicolumn{2}{|c|}{0.169} & & \\
\hline \multicolumn{5}{|l|}{ PFBA } \\
\hline LBM (kg) & 0.016 & 0.002 & 0.288 & $<0.0001$ \\
\hline $\begin{array}{l}\text { Handgrip } \\
\text { strength }(\mathrm{kg})\end{array}$ & $0 \cdot 174$ & 0.051 & 0.041 & 0.001 \\
\hline FBM (kg) & -0.004 & 0.002 & 0.021 & 0.007 \\
\hline Constant & $1 \cdot 175$ & 0.135 & & $<0.0001$ \\
\hline Adjusted $R^{2}$ & \multicolumn{2}{|c|}{0.341} & & \\
\hline
\end{tabular}

${ }^{*}$ For details of subjects and procedures, see Materials and methods.

TB, total body; LBM, lean body mass; FBM, fat body mass; DF, distal forearm; PF, proximal forearm.
BMC for the total body accounted for only $2.9 \%$ of the variance for BMC.

Height $(P<0.0001)$, LBM $(P<0.0001)$ and FBM $(P<0 \cdot 05)$ were significant independent determinants for total body BA (Table 3). All these body composition parameters contributed about $70 \%$ of the variance for total body BA. In contrast, neither dietary $\mathrm{Ca}$ nor physical activity had any influence as independent predictors of total body BA. Handgrip muscle strength $(P<0.0001)$, total height $(P<0.0001)$ and pubertal breast stage $(P<0.05)$ were strong independent predictors of the distal forearm BA, accounting for $17 \%$ of the variance for distal forearm BA, while LBM $(P<0.0001)$, handgrip strength $(P<0.01)$ and FBM $(P<0.01)$ were significant independent predictors of proximal forearm BA. All these variables accounted for $34 \%$ of the total BA variance at the proximal forearm. The strength of the positive associations for physical activity levels on body mass measurements at all skeletal sites by univariate analysis (L.H. Foo, unpublished results) were mostly attenuated after further adjusting for body composition parameters and handgrip muscle strength in the full multivariate regression models, except for proximal forearm BMC. Comparisons between subjects across three tertiles of physical activity levels and body composition measures of LBM and percentage body fat and handgrip muscle strength showed that subjects in the highest tertile of physical activity had significantly greater LBM $(P<0.0001)$ and handgrip muscle strength $(P<0.0001)$ than those in the lowest tertile of physical activity level (Table 4). In contrast, there were no significant differences in percentage body fat between subjects in the highest or lowest level of physical activity, indicating that subjects in the highest level of physical activity were taller, heavier, leaner and with greater handgrip muscle strength than those with the lowest physical activity levels. There were no significant interactions between dietary $\mathrm{Ca}$ and physical activity on total body and forearm bone mass measurements and no significant independent predictor was found between pubertal stage and any of the bone variables at skeletal sites, except for distal forearm BA.

\section{Discussion}

There is little information for China, comparable to other populations, about whether variations in body composition and the level of physical activity influence skeletal growth in older adolescent girls. If such associations were found, this could help develop strategies to optimise bone mass accumulation during adolescence.

In this investigation, LBM and FBM were statistically significant predictors of BMC and BA at all skeletal sites measured. Body size and bone size emerged as the greatest independent determinants of BMC at all sites and accounted for $41 \%$ to $76 \%$, respectively, of the total variance in BMC. The present findings show that both LBM and FBM contributed the greatest variance to BMC and BA of the total body and the distal and proximal forearm, in line with other reports of growing children and adolescents $^{14-16}$. However, in the present study, LBM was found to be a much stronger independent determinant than FBM of BMC and BA at all of the skeletal sites measured. About $84 \%$ of the variance in total body BMC and $85 \%$ of that for BMD was explained by LBM, whereas fat mass accounted for only 3-11\% total variance for either BMC or BA. This association remained highly 
Table 4. Relationship between body composition measures and handgrip muscle strength and physical activity levels in Chinese girls $\dagger$

(Mean values and standard deviations for 283 subjects)

\begin{tabular}{|c|c|c|c|c|c|c|c|}
\hline & \multicolumn{2}{|c|}{ Tertile 1 (Low) } & \multicolumn{2}{|c|}{ Tertile 2 (Moderate) } & \multicolumn{2}{|c|}{ Tertile 3 (High) } & \multirow[b]{2}{*}{$P$ values } \\
\hline & Mean & SD & Mean & SD & Mean & SD & \\
\hline BMI $\left(\mathrm{kg} / \mathrm{m}^{2}\right)$ & $20 \cdot 7^{* *}$ & 3.6 & $20 \cdot 9$ & $3 \cdot 2$ & $22 \cdot 1$ & 3.3 & 0.007 \\
\hline Lean body mass $(\mathrm{kg})$ & $31 \cdot 7^{\star \star \star}$ & $4 \cdot 7$ & $32 \cdot 6^{\star \star \star}$ & $3 \cdot 8$ & $35 \cdot 2$ & $4 \cdot 6$ & $<0.0001$ \\
\hline$\%$ body fat & $35 \cdot 1$ & $5 \cdot 1$ & $35 \cdot 0$ & 5.9 & 35.4 & $5 \cdot 8$ & 0.856 \\
\hline Handgrip muscle strength $(\mathrm{kg})$ & $21 \cdot 7^{\star \star \star}$ & $3 \cdot 6$ & $23 \cdot 0^{\star \star \star}$ & 3.7 & $25 \cdot 5$ & $4 \cdot 2$ & $<0.0001$ \\
\hline
\end{tabular}

Mean values were significantly different from the highest tertile of physical activity group; ${ }^{\star \star} P<0.01 ;{ }^{\star \star \star} P<0.0001$ (one-factor ANOVA post hoc Bonferroni's test). †For details of subjects and procedures, see Materials and methods.

significant after adjusting for other known confounding variables. A study of twin pre- and post-menarcheal adolescent girls also found that LBM was a stronger determinant than FBM of total body $\mathrm{BMC}^{14}$. Similarly in Caucasian ${ }^{17,18}$ and Chinese adolescent boys and girls aged 12 to 16 years $^{3}$, there was a positive association between LBM and BMC and BMD.

Handgrip muscle strength also emerged as a strong independent determinant of BMC of the proximal forearm and of BA measured at both the distal and proximal forearm. This association remained significant when adjusted in multivariate analysis for other known confounding factors. In contrast, there was no significant association between handgrip muscle strength and any of the bone variables for the total body, suggesting that the influence of muscle strength on bone mass is more site specific rather than systemic. The present results are in line with other studies in young women, which reported a positive correlation between handgrip strength and radius BMD, but not BMD at other skeletal sites ${ }^{19,20}$. A mechanism to explain the relationship between muscle strength as related to bone mass development has not yet been found. However, studies in female twin pairs and in elderly women have suggested that interactions between muscle strength and bone mass may be under genetic control $^{21}$. Although the present study cannot rule out a possible genetic influence, the findings do support the mechanostat model of bone development, which proposes that muscle and bone form a functional unit in which greater muscular strength leads to increased bone strength and mass ${ }^{22,23}$.

Of all the dietary components examined, only milk intake was found to be a significant determinant of BMC for the total body and the distal and proximal forearm, in agreement with earlier studies ${ }^{15,24}$. Despite the obvious link between milk $\mathrm{Ca}$ intake and bone mineralisation, other components of milk, such as insulin-like growth factor I and basic milk protein, have also been suggested to influence actual bone growth $^{25,26}$. Milk may also have contributed to the overall nutritional quality of the diet and thus had a growth-promoting effect on bone mass. In contrast, total dietary $\mathrm{Ca}$ intake was not a predictor of any of the bone measurements, perhaps because for most subjects total $\mathrm{Ca}$ intake was below that recommended (1000 mg per d) for maximum Ca accretion ${ }^{27,28}$.

Regular participation in physical activity with mechanical loading causes an osteogenic response in bone, reducing the rate of bone turnover and stimulating bone formation at cortical and trabecular surfaces and thus leading to an increase in bone mass ${ }^{29}$. In the previous study of the same cohort of girls, at the age of 9 to 11 years, the physical activity score was a positive predictor of BMC and BMD at the distal and proximal forearm as well as of BMD of the total body ${ }^{30}$. Similar findings have also been reported for Caucasian adolescents ${ }^{31}$. However, exercise assessment in that study did not distinguish between the type, frequency and intensity of mechanical forces in the different physical activities. Furthermore, most other studies did not distinguish between exercise at school and that in leisure time. Different physical activities vary in their effects on bone mass accretion and development ${ }^{29,32}$. Therefore, our questionnaire gathered information on the type, frequency and impact intensity of physical activities. After adjusting for body composition and muscle strength, no significant association was found between physical activity levels and any bone mass measurements, other than a link between non-impact physical activity and proximal forearm BMC. This result is similar to that found with Chinese adolescents in Hong Kong, where neither the physical activity level nor participation in sport had any influence on bone mass of the lumbar spine and forearm ${ }^{33}$. This contrasts with observations of Caucasian children and adolescents, where the nature, magnitude and duration of weight-bearing physical activity and/or strength resistance training have been found to be positively related to bone mass acquisition ${ }^{34,35}$. These differences between studies of Chinese and Caucasian children may be related to the duration and magnitude of mechanical forces as well as the intensity of the physical activities, which were all lower in the Chinese girls and may not have been of sufficient force to induce osteogenic responses.

Most of the subjects had a more sedentary lifestyle compared with Caucasian subjects in the other investigations. Only a small part of the total time for exercise was spent in activities of high impact intensity (27\%) and only $16 \%$ of the subjects participated in organised sports, both of which were much lower than found with Caucasian girls of comparable age in Western countries ${ }^{16}$. This low participation rate in physical activity by the present subjects was mostly related to the considerable time spent in study because of social pressure to achieve scholastic success in China. This finding is similar to that previously reported in the national survey of Chinese adolescents throughout all provinces of China $^{36}$. Nevertheless, significant associations were found in the present subjects between physical activity levels and both the LBM and handgrip muscle strength, which suggests that these respond to physical activity independent of the intensity of that exercise. 
Because this was a cross-sectional study, no clear cause and effect association between body composition, muscle strength and physical activity and bone mass status can be established. The dual-energy X-ray absorptiometry scan technique for assessing bone mass growth and development in children and adolescents does not measure bone geometry and structural properties of the skeleton and provides only a two-dimensional rather than three-dimensional analysis. It is therefore possible that lifestyle or dietary factors, which might have affected bone strength and geometry, might not have been identified. Therefore, future longitudinal studies need to use more advanced bone densitometry techniques including peripheral quantitative computed tomography to determine whether modifiable lifestyle factors affect bone strength and its geometric properties in growing children and adolescents.

\section{Conclusion}

In conclusion, the present findings demonstrate that LBM, FBM, handgrip muscle strength and milk intake were all significant independent determinants of BMC and BA of the total body and/or forearm sites. However, LBM was found to be a much stronger independent determinant than FBM of BMC and BA at all skeletal sites. The only significant determinant found between handgrip muscle strength and bone mineral was between handgrip muscle strength and forearm BMC and BA. This suggested that the influence of muscle strength on bone mass is more site specific rather than systemic. Furthermore, there were significant associations between physical activity levels and handgrip muscle strength and LBM, indicating that greater muscle strength and LBM may be the result of a higher level of physical activity. Therefore, promoting healthy lifestyle practices, such as an adequate intake of high $\mathrm{Ca}$ foods and continuous participation in physical activity, should be encouraged throughout adolescence to optimise bone growth during this period.

\section{Acknowledgements}

This study was supported by the Nestlé Foundation and Danone China. The authors are grateful to all personnel involved from the National Institute for Nutrition and Food Safety, China Centers for Disease Control, Department of School Health, Xichen District of Beijing, Department of Nuclear Medicine, Hospital No. 304, school headmasters and school nurses for their full cooperation throughout the fieldwork of data collection and biochemical analyses. L.H. Foo is the recipient of a $\mathrm{PhD}$ scholarship from the University Science Malaysia through its Academic Staff Training Scheme (ASTS) Fellowship programme.

\section{References}

1. Heaney RP, Abrams S, Dawson-Hughes B, Looker A, Marcus R, Matkovic V \& Weaver C (2000) Peak bone mass. Osteoporos Int 11, 985-1009.

2. Cooper C, Campion G \& Melton LJ III (1992) Hip fractures in the elderly: a worldwide projection. Osteoporosis Int 2, $285-289$.

3. Afghani A, Xie B, Wiswell RA, Gong J, Li Y \& Johnson CA (2003) Bone mass of Asian adolescents in China: Influence of physical activity and smoking. Med Sci Sports Exerc 35, $720-729$.

4. Du X, Zhu K, Trube A, Zhang Q, Ma G, Hu X, Fraser DR \& Greenfield H (2004) School-milk intervention trial enhances growth and bone mineral accretion in Chinese girls aged 10-12 years in Beijing. Br J Nutr 92, 159-168.

5. Zhu K, Zhang Q, Foo LH, Trube A, Ma G, Hu X, Du X, Cowell CT, Fraser DR \& Greenfield H (2006) Growth, bone mass, and vitamin D status of Chinese adolescent girls 3 y after withdrawal of milk supplementation. Am J Clin Nutr 83, 714-721.

6. Tanner JM (1962) Growth at Adolescence, 2nd ed. Oxford, UK: Blackwell Scientific.

7. Greulich WW \& Pyle SI (1959) Radiographic Atlas of Skeletal Development of the Hand and Wrist, 2nd ed. Stanford, CA: Stanford University Press.

8. Prentice A, Parsons TJ \& Cole TJ (1994) Uncritical use of bone mineral density in absorptiometry may lead to size-related artifacts in the identification of bone mineral determinants. Am J Clin Nutr 60, 837-842.

9. Aaron DJ, Kriska AM, Dearwater SR, Cauley JA, Metz KF \& LaPorte RE (1995) Reproducibility and validity of an epidemiologic questionnaire to assess past year physical activity in adolescents. Am J Epidemiol 142, 191-201.

10. Ma GS, Liu AL, Zhang Q \& Hu XQ (2002) The physical activity pattern of elementary female students living in Xichen District of Beijing. Chin J School Doctor 16, 292-294.

11. Jakes RW, Khaw K, Day NE, Bingham S, Welch A, Oakes S, Luben R, Dalzell N, Reeve J \& Wareham NJ (2001) Patterns of physical activity and ultrasound attenuation by heel bone among Norfolk cohort of European Prospective Investigation of Cancer (EPIC Norfolk): population based study. BMJ 322, 140.

12. Holland B, Welch AA, Unwin ID, Buss DH, Paul AA \& Southgate DA (1991) McCance and Widdowson's the Composition of Food, 5th ed. London: Royal Society of Chemistry and Ministry of Agriculture, Fisheries and Food.

13. Cole TJ, Bellizzi MC, Flegal KM \& Dietz WH (2000) Establishing a standard definition for child overweight and obesity worldwide: international survey. BMJ 320, 1240-1243.

14. Young D, Hopper JL, Nowson CA, Green RM, Sherwin JA, Kaymakci B, Smid M, Guest CS, Larkins RG \& Wark JD (1995) Determinants of bone mass in 10- to 26-year-old females: a twin study. J Bone Miner Res 10, 558-567.

15. Ilich JZ, Skugor M, Hangartner T, Boashe A \& Matkovic V (1998) Relation of nutrition, body composition and physical activity to skeletal development: a cross-sectional study in preadolescent females. J Am Coll Nutr 17, 136-147.

16. McKay HA, Petit MA, Khan KM \& Schutz RW (2000) Lifestyle determinants of bone mineral: a comparison between prepubertal Asian- and Caucasian-Canadian boys and girls. Calcif Tissue Int 66, 320-324.

17. Faulkner RA, Bailey DA, Drinkwater DT, Wilkinson AA, Houston CS \& McKay HA (1993) Regional and total body bone mineral content, bone mineral density and total body tissue composition in children 8-16 years of age. Calcif Tissue Int 53, 7-12.

18. Valdimarsson O, Kristinsson JO, Stefansson SO, Valdimarsson S \& Sigurdsson G (1999) Lean mass and physical activity as predictors of bone mineral density in 16-20-year old women. J Intern Med 245, 489-496.

19. Beverly M, Rider T, Evans M \& Smith R (1989) Local bone mineral response to brief exercise that stresses the skeleton. BMJ 299, 657-665.

20. Snow-Harter C, Bouxsein M, Lewis B, Charette S, Weinstein P \& Marcus R (1990) Muscle strength as a predictor of bone mineral density in young women. J Bone Miner Res 5, 589-595.

21. Seeman E, Hopper JL, Young NR, Formica C, Goss P \& Tsalamandris C (1996) Do genetic factors explain associations 
between muscle strength, lean mass and bone density? A twin study. Am J Physiology 270, E320-E327.

22. Burr DB (1997) Muscle strength, bone mass, and age-related bone loss. J Bone Miner Res 12, 1547-1551.

23. Frost HM (2003) Bone's mechanostat: a 2003 update. Anat Rec A Discov Mol Cell Evol Biol 275, 1081-1101.

24. Du XQ, Greenfield H, Fraser DR, Ge KY, Liu ZH \& He W (2002) Milk consumption and bone mineral content in Chinese adolescent girls. Bone 30, 521-528.

25. Philipps AF, Dvorak B, Kling PJ, Grille JG \& Koldovsky O (2000) Absorption of milk-borne insulin-like growth factor-I into portal blood of suckling rats. J Pediatr Gastroenterol Nutr 31, 128-135.

26. Toba Y, Takada Y, Matsuoka Y, et al. (2001) Milk basic protein promotes bone formation and suppresses bone resorption in healthy adult men. Biosci Biotechnol Biochem 65, $1353-1357$.

27. Matkovic V \& Heaney RP (1992) Calcium balance during human growth: evidence for threshold behavior. Am J Clin Nutr 55, 992-996.

28. Chinese Nutrition Society (2000) Recommended Dietary Allowance for Chinese. Beijing: CNS.

29. Turner $\mathrm{CH} \&$ Robling AG (2003) Designing exercise regimens to increase bone strength. Exerc Sport Sci Rev 31, 45-50.

30. Zhu K, Du X, Greenfield H, Zhang Q, Ma G, Hu X \& Fraser DR (2004) Bone mass in Chinese premenarcheal girls: the roles of body composition, calcium intake and physical activity. $\mathrm{Br} J$ Nutr 92, 985-993.

31. Vatanparast H, Baxter-Jones A, Faulkner RA, Bailey DA \& Whiting SJ (2005) Positive effects of vegetable and fruit consumption and calcium intake on bone mineral accrual in boys during growth from childhood to adolescence: the University of Saskatchewan Pediatric Bone Mineral Accrual Study. Am J Clin Nutr 82, 700-706.

32. Rubin CT \& Lanyon LE (1985) Regulation of bone mass by mechanical strain magnitude. Calcif Tiss Int 37, 411-417.

33. Cheng JC, Maffulli N, Leung SS, Lee WTK, Lau JT \& Chan KM (1999) Axial and peripheral bone mineral acquisition: A 3-year longitudinal study in Chinese adolescents. Eur $J$ Pediatr 158, 506-512.

34. Welten DC, Kemper HCG, Bertheke Post GB, van Mechelen W, Twisk J, Lips P \& Teule TJ (1994) Weight-bearing activity during youth is a more important factor for peak bone mass than calcium intake. J Bone Miner Res 9, 1089-1095.

35. Boot AM, de Ridder MA, Pols HA, Krenning EP \& de Muinck Keizer-Schrama SM (1997) Bone mineral density in children and adolescents: relation to puberty, calcium intake and physical activity. J Clin Endocrinol Metab 82, 57-62.

36. Tudor-Locke C, Ainsworth BE, Adair LS, Du S \& Popkin BM (2003) Physical activity and inactivity in Chinese school-aged youth: the China Health and Nutrition Survey. Int J Obes Relat Metab Disord 27, 1093-1099. 